\title{
GAMBARAN FUNGSI KOGNITIF PADA PASIEN RAWAT JALAN DENGAN RIWAYAT STROKE DI POLIKLINIK SARAF RSUP PROF. DR. R.D. KANDOU MANADO
}

\author{
${ }^{1}$ Tirzha N. Paparang \\ ${ }^{2}$ Corry N. Mahama \\ ${ }^{3}$ Denny J. Ngantung
}

\author{
${ }^{1}$ Kandidat Skripsi Fakultas Kedokteran Universitas Sam Ratulangi Manado \\ ${ }^{2}$ Bagian Neurologi Fakultas Kedokteran Universitas Sam Ratulangi Manado \\ ${ }^{3}$ Bagian Neurologi RSUP Prof. Dr. R.D. Kandou Manado \\ Email: tirzhapaparang09317@yahoo.com
}

\begin{abstract}
Stroke is a major cause of cognitive dysfunction. The incidences of cognitive dysfunction increase three-fold after strokes, usually involving impairement of abilities in visuo-spacial, memory, orientation, speech, attention, and performance functions. The rapid, practical, and approved examinations used to evaluate and confirm the decline in cognitive functions are the Mini Mental State Examination (MMSE), the Clock Drawing Test (CDT), and the Trail Making Test (TMT). This study aimed to reveal the cognitive functions of outpatients with stroke histories in the Neurology Polyclinic, Prof. Dr. R.D. Kandou Hospital Manado by using the above mentioned examinations. This was a descriptive study with a cross-sectional design conducted in November 2012. The results showed that there were 51 respondents who fulfilled the inclusion criteria consisting of 32 males and 19 females. The highest decline of cognitive function by age, the educational level, and employment was 6079 years, more than 9 years of education, and retired workers, respectively. The results of the MMSE, CDT, and TMT examinations for cognitive impairment evaluation were as follow: MMSE 62.75\%, CDT 56.86\%, TMT A 96.08\%, and TMT B 84.31\%. Conclusion: Most of the outpatients with stroke histories in the Neurology Polyclinic, Prof. Dr. R.D. Kandou Hospital Manado showed cognitive impairments.

Keywords: CDT, cognitive function, MMSE, stroke, TMT-A and B
\end{abstract}

\begin{abstract}
Abstrak: Stroke merupakan penyebab utama gangguan fungsi kognitif. Insiden gangguan kognitif meningkat tiga kali lipat setelah stroke, dan biasanya melibatkan kemampuan visuospasial, memori, orientasi, bahasa, perhatian dan fungsi eksekutif. Pemeriksaan yang digunakan untuk mengevaluasi dan mengonfirmasi penurunan fungsi kognitif yang cepat dan praktis namun bernilai tinggi ialah Mini Mental State Examination (MMSE), Clock Drawing Test (CDT), dan Trail Making Test (TMT). Penelitian ini bertujuan untuk mengetahui gambaran fungsi kognitif pada pasien rawat jalan dengan riwayat stroke di Poliklinik Saraf RSUP Prof. Dr. R.D. Kandou Manado. Penelitian ini bersifat deskriptif dengan crosssectional design dan dilaksanakan selama bulan November 2012. Hasil penelitian memperlihatkan bahwa 51 responden memenuhi kriteria inklusi, terdiri dari 32 laki-laki dan 19 perempuan. Berdasarkan usia, tingkat pendidikan, dan pekerjaan, penurunan fungsi kognitif terbanyak pada usia 60-79 tahun, tingkat pendidikan terakhir $>9$ tahun, dan pekerjaan pensiunan. Hasil pemeriksaan MMSE, CDT, dan TMT terhadap fungsi kognitif responden ialah: MMSE 62,75\%, CDT 56,86\%, TMT A 96,08\%, dan TMT B 84,31\%. Simpulan: Sebagian besar pasien rawat jalan dengan riwayat stroke di Poliklinik Saraf RSUP Prof. Dr. R.D. Kandou Manado telah memperlihatkan gagguan fungsi kognitif.

Kata kunci: stroke, fungsi kognitif, MMSE, CDT, TMT-A dan B
\end{abstract}


Stroke adalah manifestasi klinis dari gangguan fungsi serebral, baik fokal maupun menyeluruh, yang berlangsung dengan cepat, berlangsung lebih dari 24 jam, atau berakhir dengan maut, tanpa ditemukannya penyebab selain daripada gangguan vaskular. ${ }^{1}$ Stroke dapat ditemukan pada semua golongan usia, namun sebagian besar pada usia di atas 55 tahun. $^{2}$

Angka kejadian stroke meningkat secara dramatis seiring usia. Setiap penambahan usia 10 tahun sejak usia 35 tahun, risiko stroke meningkat dua kali lipat. Sekitar 5\% orang berusia di atas 65 tahun pernah mengalami setidaknya satu kali stroke. ${ }^{3}$ Menurut WHO, diperkirakan secara global terdapat 16,3 juta kejadian stroke baru setiap tahunnya. Dari jumlah tersebut, 11,2 juta kasus ditemukan di negara berkembang, sedangkan 5,1 juta ditemukan di negara maju (Amerika Utara, Eropa, Jepang, Australia, dan Selandia Baru). ${ }^{4}$ Di Indonesia, setiap 1000 orang, 8 orang diantaranya terkena stroke. Stroke merupakan penyebab utama kematian pada semua usia, dengan proporsi $15,4 \%$. Setiap 7 orang yang meninggal di Indonesia, 1 diantaranya karena stroke. ${ }^{5}$ Data Riskesdas 2007 menunjukkan diperkotaan, kematian akibat stroke sebesar 15,9\%, sedangkan di pedesaan sebesar $11,5 \%{ }^{6}$

Stroke merupakan penyebab utama gangguan kognitif. Insiden gangguan kognitif meningkat tiga kali lipat setelah stroke, biasanya melibatkan kemampuan visuospasial, memori, orientasi, bahasa, perhatian, dan fungsi eksekutif. ${ }^{7,8}$ Beberapa faktor (faktor risiko stroke serta karakteristik klinis dan radiologi stroke) berkontribusi pada risiko penurunan kognitif sesudah suatu cedera serebrovaskular.

Penurunan fungsi kognitif terjadi pada $35,2-43,9 \%$ dari pasien stroke setelah tiga bulan, dan bisa berlanjut untuk waktu yang lama pada sekitar 1/3 dari pasien. Penurunan kognitif dapat menyebabkan menurunnya kemampuan fungsional. Beberapa peneliti melaporkan bahwa penurunan kognitif berpengaruh negatif terhadap kualitas hidup penderita karena dapat mengganggu aktivitas kehidupan sehari-hari (activity of daily living). ${ }^{9}$

Dalam menilai aspek kognitif pada pasien rawat jalan yang mempunyai riwayat stroke di RSUP. Prof. Dr. R.D. Kandou Manado, digunakan the mini mental state examination (MMSE), clock drawing test (CDT), dan trail making test (TMT) sebagai metode pemeriksaan untuk evaluasi dan konfirmasi penurunan fungsi kognitif. Selain itu, metode ini juga dapat digunakan untuk memantau perjalanan penyakit. MMSE merupakan pemeriksaan yang mudah dan cepat dikerjakan berupa 30 point-test terhadap fungsi kognitif, dan berisikan pula uji orientasi, memori kerja, memori episodik, komprehensi bahasa, serta menyebutkan kata dan mengulang kata. CDT merupakan tes yang menguji kemampuan pemahaman, kemampuan visual spasial, kemampuan merekonstruksi, konsentrasi, pengetahuan angka, ingatan visual, dan fungsi eksekutif. TMT digunakan secara luas untuk menilai fungsi eksekutif pada pasien stroke, dan terdiri atas bagian A dan bagian B. ${ }^{10,11}$

\section{METODE PENELITIAN}

Penelitian ini bersifat deskriptif dengan cross-sectional design. Data primer untuk mengetahui gambaran fungsi kognitif pada pasien rawat jalan dengan riwayat stroke diambil dari Poliklinik Saraf RSUP Prof. Dr. R.D. Kandou Manado periode November 2012. Variabel penelitian ialah fungsi kognitif, jenis kelamin, umur, pendidikan terakhir, dan pekerjaan. Subjek penelitian ini ialah pasien dengan riwayat stroke yang datang kontrol ke Poliklinik Saraf. Kriteria inklusi ialah memiliki riwayat stroke hemoragik atau nonhemoragik, sedangkan kriteria eksklusi ialah memiliki riwayat gangguan psikiatrik dan tidak bersedia mengikuti penelitian. Subjek yang memenuhi kriteria penelitian diperiksa dengan menggunakan MMSE, CDT, dan TMT. Data yang dikumpulkan diolah menggunakan SPSS 20 untuk mengetahui distribusi frekuensi masingmasing variabel dan hasilnya ditampilkan dalam bentuk tabel dan grafik. 


\section{HASIL PENELITIAN}

Penelitian ini dilaksanakan di Poliklinik Saraf RSUP. Prof. Dr. R.D. Kandou Manado, selama bulan November 2012. Pada pengambilan data didapatkan 51 responden dengan riwayat stroke yang memenuhi kriteria penelitian.

\section{Distribusi responden berdasarkan jenis kelamin, usia, dan pendidikan}

Dalam penelitian ini jumlah responden jenis kelamin laki-laki 32 orang $(62,7 \%)$ dan jenis kelamin perempuan 19 orang $(37,3 \%)$. Sebagian besar responden berusia 60-79 tahun $(51 \%)$, tetapi yang berusia 40 59 tahun juga cukup banyak (Tabel 1). Umumnya responden mempunyai masa pendidikan $>9$ tahun $(76,5 \%)$ (Tabel 2$)$.

Tabel 1. Distribusi responden berdasarkan usia.

\begin{tabular}{lcc}
\hline Usia (tahun) & Jumlah & \% \\
\hline $20-39$ & 0 & 0,0 \\
$40-59$ & 24 & 47,1 \\
$60-79$ & 26 & 51,0 \\
$\geq 80$ & 1 & 2,0 \\
TOTAL & 51 & 100 \\
\hline
\end{tabular}

Tabel 2. Distribusi responden berdasarkan masa pendidikan.

\begin{tabular}{lcc}
\hline $\begin{array}{c}\text { Pendidikan } \\
\text { terakhir }\end{array}$ & Jumlah & $\boldsymbol{\%}$ \\
\hline$\leq 9$ tahun & 12 & 23,5 \\
$>9$ tahun & 39 & 76,5 \\
TOTAL & 51 & 100,0 \\
\hline
\end{tabular}

Tabel 3. Distribusi responden berdasarkan pekerjaan.

\begin{tabular}{llc}
\hline Pekerjaan & Jumlah & \% \\
\hline Buruh/Tani & 3 & 5,9 \\
PNS & 7 & 13,7 \\
Pensiunan & 24 & 47,1 \\
Wiraswasta & 1 & 2,0 \\
Swasta & 7 & 13,7 \\
IRT & 7 & 13,7 \\
Tdk bekerja & 2 & 3,9 \\
TOTAL & 51 & 100 \\
\hline
\end{tabular}

Dari segi pekerjaan responden, pensiunan yang paling sering ditemukan $(47,1 \%)$, sedangkan PNS, swasta, dan IRT berjumlah sama dan menempati posisi kedua (Tabel 3).

\section{Hasil pemeriksaan fungsi kognitif}

\section{Hasil Pemeriksaan MMSE}

Hasil MMSE menunjukkan bahwa yang terbanyak ialah gangguan kognitif ringan $(45,10 \%)$, sedangkan kategori gangguan kognitif berat tidak ditemukan (Gambar 1, Tabel 4).

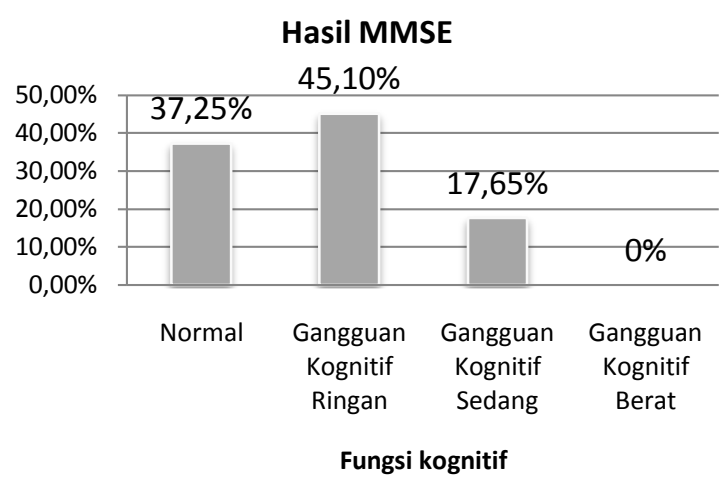

Gambar 1. Grafik pemeriksaan MMSE pada pasien dengan riwayat stroke.

\section{Hasil pemeriksaan CDT}

Hasil pemeriksaan CDT menunjukkan 29 orang $(56,86 \%)$ termasuk dalam kategori fungsi kognitif terganggu dan 22 orang $(43,14 \%)$ termasuk dalam kategori fungsi kognitif tidak terganggu (Gambar 2, Tabel 5).

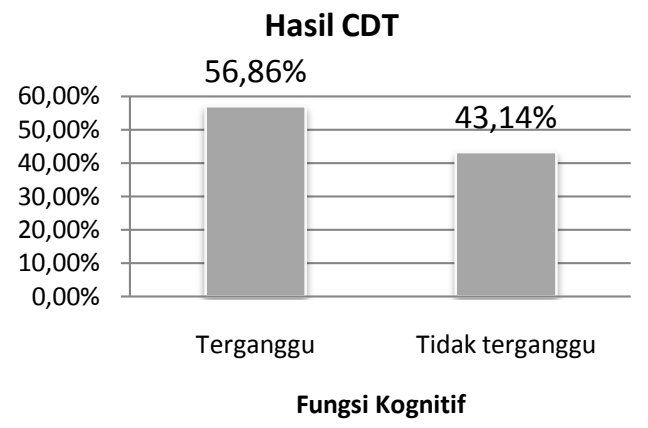

Gambar 2. Grafik pemeriksaan CDT pada pasien dengan riwayat stroke. 
S144 Jurnal Biomedik (JBM), Volume 5, Nomor 1, Suplemen, Maret 2013, hlm. S141-147

Tabel 4. Hasil pemeriksaan MMSE berdasarkan jenis kelamin, usia, pendidikan, dan pekerjaan.

\begin{tabular}{lccccccccc}
\hline \multirow{2}{*}{ Variabel } & \multicolumn{2}{c}{ Normal } & \multicolumn{2}{c}{ GK ringan } & \multicolumn{3}{c}{ GK sedang } & \multicolumn{2}{c}{ GK berat } \\
\cline { 2 - 9 } & $\mathbf{n}$ & $\mathbf{\%}$ & $\mathbf{n}$ & $\mathbf{\%}$ & $\mathbf{n}$ & $\mathbf{\%}$ & $\mathbf{n}$ & $\mathbf{\%}$ \\
\hline Jenis kelamin & & & & & & & & \\
Laki-laki & 11 & 34,37 & 15 & 46,88 & 6 & 18,75 & 0 & 0 \\
$\quad$ Perempuan & 8 & 42,11 & 8 & 42,11 & 3 & 15,79 & 0 & 0 \\
Usia & & & & & & & & \\
40-59 & 9 & 37,5 & 12 & 50 & 3 & 12,5 & 0 & 0 \\
60-79 & 9 & 34,6 & 11 & 46,3 & 6 & 23,1 & 0 & 0 \\
$\geq 80$ tahun & 1 & 100 & 0 & 0 & 0 & 0 & 0 & 0 \\
Pendidikan & & & & & & & & \\
$\leq 9$ tahun & 5 & 41,7 & 4 & 33,3 & 3 & 25,0 & 0 & 0 \\
$>9$ tahun & 14 & 35,9 & 19 & 48,7 & 6 & 17,6 & 0 & 0 \\
Pekerjaan & & & & & & & & \\
Buruh/Tani & 2 & 66,7 & 0 & 0 & 1 & 33,33 & 0 & 0 \\
PNS & 4 & 57,1 & 2 & 28,6 & 1 & 14,3 & 0 & 0 \\
Pensiunan & 8 & 33,3 & 2 & 50 & 14 & 16,7 & 0 & 0 \\
Wiraswasta & 0 & 0 & 1 & 100 & 0 & 0 & 0 & 0 \\
Swasta & 1 & 14,3 & 4 & 57,1 & 2 & 28,6 & 0 & 0 \\
IRT & 4 & 57,1 & 3 & 42,9 & 0 & 0 & 0 & 0 \\
Tdk bekerja & 0 & 0 & 1 & 50 & 1 & 50 & 0 & 0 \\
\hline
\end{tabular}

Ket: GK = Gangguan Kognitif

Tabel 5. Hasil pemeriksaan CDT berdasarkan jenis kelamin, golongan usia, pendidikan, dan pekerjaan.

\begin{tabular}{lcccc}
\hline \multirow{2}{*}{ Variabel } & \multicolumn{2}{c}{ Normal } & \multicolumn{2}{c}{ Terganggu } \\
\cline { 2 - 5 } & $\mathbf{n}$ & $\mathbf{\%}$ & $\mathbf{n}$ & $\mathbf{\%}$ \\
\hline Jenis kelamin & & & & \\
Laki-laki & 15 & 46,88 & 17 & 53.12 \\
$\quad$ Perempuan & 7 & 36,84 & 12 & 63.16 \\
Usia & & & & \\
40-59 & 12 & 50 & 12 & 50 \\
$60-79$ & 10 & 38,5 & 16 & 61,5 \\
$\geq 80$ & 0 & 0 & 1 & 100 \\
Pendidikan & & & & \\
$\leq 9$ tahun & 4 & 33,3 & 8 & 66,7 \\
$>9$ tahun & 18 & 46,2 & 21 & 53,8 \\
Pekerjaan & & & & \\
Buruh/Tani & 1 & 33,3 & 2 & 66,7 \\
PNS & 6 & 85,7 & 1 & 14,3 \\
Pensiunan & 10 & 41,7 & 14 & 58,3 \\
Wiraswasta & 1 & 100 & 0 & 0 \\
Swasta & 2 & 28,6 & 5 & 71,4 \\
IRT & 2 & 28,6 & 5 & 71,4 \\
Tdk bekerja & 0 & 0 & 2 & 100 \\
\hline
\end{tabular}

\section{Hasil pemeriksaan TMT}

Hasil pemeriksaanTMT baik TMT-A maupun TMT-B menunjukkan bahwa sebagian besar responden termasuk dalam kategori fungsi kognitif terganggu, yaitu 96,08\% untuk TMT-A dan 84,31\% untuk TMT-B (Gambar 3, Tabel 6).

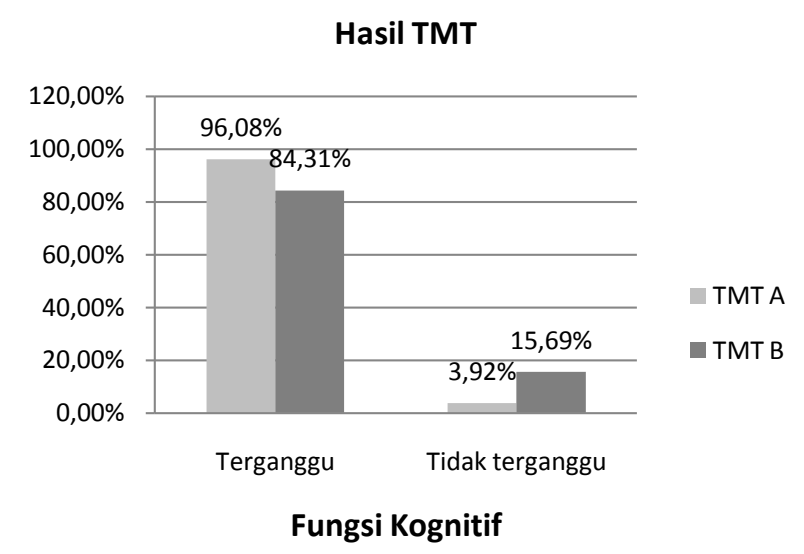

Gambar 3. Grafik pemeriksaan TMT-A dan TMT-B pada pasien dengan riwayat stroke. 
Tabel 6. Hasil pemeriksaan TMT-A dan TMT-B berdasarkan jenis kelamin, golongan umur, pendidikan, dan pekerjaan.

\begin{tabular}{lcccccccc}
\hline \multirow{2}{*}{ Variabel } & \multicolumn{4}{c}{ TMT-A } & \multicolumn{5}{c}{ TMT-B } \\
\cline { 2 - 10 } & \multicolumn{2}{c}{ Normal } & \multicolumn{2}{c}{ Terganggu } & Normal & Terganggu \\
\cline { 2 - 10 } & $\mathbf{n}$ & $\mathbf{\%}$ & $\mathbf{n}$ & $\mathbf{\%}$ & $\mathbf{n}$ & $\mathbf{\%}$ & $\mathbf{n}$ & $\mathbf{\%}$ \\
\hline Jenis kelamin & & & & & & & & \\
$\quad$ Laki-laki & 2 & 6.25 & 30 & 93.75 & 3 & 9.38 & 29 & 90.62 \\
$\quad$ Perempuan & 0 & 0 & 19 & 100 & 5 & 26.32 & & 73.68 \\
\hline Umur & & & & & & & & \\
$40-59$ & 2 & 8,3 & 22 & 91,7 & 7 & 29,2 & 17 & 70,8 \\
$60-79$ & 0 & 0 & 26 & 100 & 1 & 3,8 & 25 & 96,2 \\
$\geq 80$ & 0 & 0 & 1 & 100 & 0 & 0 & 1 & 100 \\
\hline Pendidikan & & & & & & & & \\
$\leq 9$ tahun & 0 & 0 & 12 & 100 & 1 & 8,3 & 11 & 91,7 \\
$>9$ tahun & 2 & 5,1 & 37 & 94,9 & 7 & 17,9 & 32 & 82,1 \\
\hline Pekerjaan & & & & & & & & \\
Buruh/Tani & 0 & 0 & 3 & 100 & 1 & 33,3 & 2 & 66,7 \\
PNS & 2 & 28,6 & 5 & 71,4 & 3 & 42,9 & 4 & 57,1 \\
Pensiunan & 0 & 0 & 24 & 100 & 2 & 8,3 & 22 & 91,7 \\
Wiraswasta & 0 & 0 & 1 & 100 & 0 & 0 & 1 & 100 \\
Swasta & 0 & 0 & 7 & 100 & 0 & 0 & 7 & 100 \\
IRT & 0 & 0 & 7 & 100 & 2 & 28,6 & 5 & 71,4 \\
Tdk bekerja & 0 & 0 & 2 & 100 & 0 & 0 & 2 & 100 \\
\hline
\end{tabular}

\section{BAHASAN}

Pada penelitian ini didapatkan responden laki-laki sebanyak $62,7 \%$ dan perempuan sebesar $37,3 \%$. Penelitian Mukhopadhyay et al. ${ }^{12}$ menunjukkan prevalensi gangguan kognitif pada pasien stroke dan post stroke lebih tinggi pada laki-laki daripada perempuan. ${ }^{12}$ Pada penelitian ini, hasil MMSE, CDT, dan TMT menunjukkan jenis kelamin laki-laki lebih banyak mengalami gangguan kognitif daripada perempuan (Tabel 4-6). Hal ini mungkin disebabkan jumlah responden laki-laki lebih banyak dari perempuan. Jika distribusi responden berdasarkan jenis kelamin seimbang antara laki-laki dan perempuan, mungkin akan memberikan hasil yang berbeda.

Tabel 1 memperlihatkan bahwa usia responden terbanyak yaitu 60-79 tahun $(51 \%)$ sedangkan yang terendah pada usia $\geq 80$ tahun $(2 \%)$. Hasil ini tidak sesuai dengan yang dikemukakan Yastroki $(2009)^{3}$ yaitu angka kejadian stroke meningkat seiring usia, dan sekitar 5\% orang berusia $>65$ tahun pernah mengalami setidaknya satu kali stroke. Dari data pemeriksaan MMSE, CDT, dan TMT dapat dilihat bahwa gangguan kognitif ditemukan lebih banyak pada usia 60 tahun ke atas. Robert et al. ${ }^{13}$ menyatakan bahwa prevalensi gangguan kognitif pada pasien stroke ditemukan tinggi, dan gangguan kognitif tersebut meningkat seiring dengan penambahan usia.

Tabel 2 menunjukkan bahwa tingkat pendidikan responden yang terbanyak ialah $>9$ tahun, yaitu $76,5 \%$ dari populasi total. Hasil pemeriksaan MMSE, CDT, dan TMT menunjukkan bahwa responden dengan tingkat pendidikan $>9$ tahun lebih banyak mengalami gangguan kognitif. Hal ini berbeda dengan hasil penelitian Pohjasvaara et al. ${ }^{14}$ yang mendapatkan bahwa tingkat pendidikan yang rendah merupakan salah satu faktor risiko gangguan kognitif setelah stroke.

Pada Tabel 3 terlihat bahwa pekerjaan responden yang terbanyak sebagai 
pensiunan, yaitu $47,1 \%$ dari populasi total (baik yang bekerja maupun yang tidak bekerja). Hasil pemeriksaan MMSE, CDT, dan TMT berdasarkan pekerjaan menunjukkan bahwa gangguan kognitif ditemukan lebih banyak pada pensiunan. Hasil ini sama dengan penelitian Puista $^{15}$ pada pasien post stroke di RSUP Dr. Kariadi Semarang yang menunjukkan bahwa jenis pekerjaan terbanyak ialah pensiunan, yang juga terbanyak mengalami gangguan kognitif.

Pada penelitian ini, hasil MMSE menunjukkan bahwa lebih dari setengah populasi telah mengalami gangguan fungsi kognitif baik yang ringan (45,10\%) maupun yang sedang $(17,65 \%)$. Hal ini sesuai dengan teori yang menyatakan bahwa stroke merupakan salah satu penyebab gangguan fungsi kognitif. Penelitian Robert et al. ${ }^{13}$ menunjukkan bahwa lebih dari setengah populasi telah mengalami gangguan fungsi kognitif, yaitu dari 85 pasien yang diteliti: 23 pasien (27\%) mengalami gangguan kognitif ringan, 14 pasien (16\%) mengalami gangguan kognitif sedang, 17 pasien $(20 \%)$ mengalami gangguan kognitif berat, dan 31 pasien (37\%) tidak mengalami gangguan kognitif.

Hasil CDT yang didapat menunjukkan bahwa lebih dari setengah pasien $(56,86 \%)$ telah mengalami gangguan kognitif. Hasil ini berbeda dengan penelitian Puista ${ }^{15}$ yang dilakukan di RSUP Dr. Kariadi Semarang, yang menunjukkan 49,2\% pasien mengalami gangguan kognitif, sedangkan 50,8\% pasien tidak mengalami gangguan kognitif.

Hasil TMT baik bagian A maupun bagian $\mathrm{B}$ menunjukkan bahwa hampir semua pasien telah mengalami gangguan kognitif, yaitu untuk TMT bagian A sebanyak 96,08\% dan bagian B sebanyak $84,31 \%$. Penilaian fungsi kognitif menggunakan TMT pada pasien dengan riwayat stroke belum pernah dilaporkan dalam acuan pustaka.

\section{SIMPULAN}

Dari hasil penelitian dapat disimpulkan bahwa sebagian besar pasien rawat jalan dengan riwayat stroke di Poliklinik Saraf RSUP Prof. Dr. R.D. Kandou Manado telah memperlihatkan gagguan fungsi kognitif.

\section{SARAN}

Perlu dilakukan penelitian lanjutan dengan desain kohort, serta jumlah sampel dan variabel yang lebih luas. Deteksi gangguan kognitif pada pasien dengan riwayat stroke selain dengan pemeriksaan MMSE, perlu juga dilengkapi dengan pemeriksaan CDT dan TMT untuk menilai fungsi eksekutif. Penanganan secara komprehensif sangat dibutuhkan oleh pasien dengan riwayat stroke yang mengalami gangguan fungsi kognitif.

\section{UCAPAN TERIMA KASIH}

Ucapan terima kasih ditujukan kepada dr. Mieke A. H. N. Kembuan, Sp.S dan dr. Junita Maja P. Sampurno, Sp.S selaku penguji Skripsi, serta semua pihak yang secara langsung maupun tidak langsung telah menumbuhkan ide atau gagasan pada penulis.

\section{DAFTAR PUSTAKA}

1. Amiruddin A, Kuswara FF, Limoa A, Wuysang G. Gambaran umum tentang gangguan peredaran darah otak (GPDO). In: Harsono, editor. Kapita Selekta Neurologi (Edisi Kedua). Yogyakarta: Gadjah Mada University Press, 2009; p.81.

2. Bustan MN. Epidemiologi: Penyakit tidak menular (Cetakan ke-2). Jakarta: Rineka Cipta; 2007.

3. Yayasan Stroke Indonesia. Pengetahuan sekilas tentang stroke [homepage on the Internet]. 2009 [cited 2012 Oct 13]. Available from: www.yastroki.or.id/ read.php?id=340.

4. Truelsen T, Bonita R. The worldwide burden of stroke: current status and future projections. In: Fisher M, editor. Handbook of Clinical Neurology Vol 92 (Third Series). Amsterdam: Elseiver, 2009; p.327.

5. Kementerian Kesehatan Republik Indonesia. 
8 dari 1000 orang di Indonesia terkena stroke [homepage on the Internet]. Oktober 2011. [cited 2012 Oct 13]. Available from: http://www.depkes.go. id/index.php/berita/press-release/17038-dari-1000-orang-di-indonesia-terke na-stroke.html.

6. Kementerian Kesehatan Republik Indonesia. Penyakit tidak menular (PTM) penyebab kematian terbanyak di Indonesia [homepage on the Internet]. Oktober 2011. [cited 2012 Oct 13]. Available from: http://www.depkes. go.id/index.php/berita/press-release/ 1637-penyakit-tidak-menular-ptmpenyebab-kematian-terbanyak-diindonesia.html.

7. Danovska M, Stamenov B, Alexandrova M, Peychinska D. Post-stroke cognitive impairment - phenomenology and prognostic factors. Journal of IMAB. 2012;18(3):290-297.

8. Merino JG, Hachinski V. Stroke related dementia. In: Barnes MP, Dobkin BH, Bogousslavsky J, editors. Recovery After Stroke. New York: Cambridge University Press, 2005; p.541.

9. Paker N, Bugdayci D, Tekdos D, Kaya B, Dere C. Impact of cognitive impairment on functional outcome in stroke. Stroke Research and Treatment [serial online]. 2010 [cited 2012 Oct 23]. Available from: doi:10.4061/2010/ 652612.

10. Rochmah W, Harimurti K. Demensia. In:
Sudoyo A, editor. Buku Ajar Ilmu Penyakit Dalam Jilid I (Edisi V). Jakarta: Interna Publishing, 2009; p.841.

11. Hartati S, Widayanti CG. Clock drawing: Asesmen untuk demensia (Studi deskriptif pada orang lanjut usia di kota Semarang). Jurnal Psikologi Undip. 2012;7(1):1-10.

12. Mukhopadhyay A, Sundar U, Adwani S, Pandit D. Prevalence of stroke and post-stroke cognitive impairment in the elderly in Dharavi, Mumbai. J Assoc Physicians India. 2012;60:29-32.

13. Mukisa R, Ddumba E, Musisi S, Kiwuwa MS. Prevalence and types of cognitive impairment among patients with stroke attending a referral hospital in Uganda. African Journal of Neurological Sciences [serial online]. 2011 [cited 2013 Aug 10];30(2). Available from http://www.ajns.paans.org/article.php3? id_article $=380$.

14. Pohjasvaara T, Erkinjuntti T, Ylikoski, Hietanen, Vataja R, Kaste M. Clinical determinants of post-stroke dementia. American Heart Association Journal. 1998;29:75-81.

15. Puista R. Kontribusi hipertensi terhadap aterosklerosis arteri karotis interna pada pasien pasca stroke iskemik [TESIS]. Semarang: Program Pascasarjana Magister Ilmu Biomedik dan Program Pendidikan Dokter Spesialis I Ilmu Penyakit Saraf Universitas Diponegoro; 2011. 